\title{
Non-Surgical Ablative Treatment of Distant Extracranial Metastases for Renal Cell Carcinoma: A Systematic Review
}

\author{
Annelies Verbiest ${ }^{\mathrm{a}, \mathrm{b}}$, Gert De Meerleer ${ }^{\mathrm{c}}$, Maarten Albersen ${ }^{\mathrm{d}}$ and Benoit Beuselinck ${ }^{\mathrm{a}, \mathrm{b}, *}$ \\ ${ }^{a}$ Department of Oncology, Laboratory of Experimental Oncology, KU Leuven, Leuven, Belgium \\ ${ }^{\mathrm{b}}$ Department of General Medical Oncology, University Hospitals Leuven, Leuven Cancer Institute, Leuven, \\ Belgium \\ ${ }^{\mathrm{c}}$ Department of Radiotherapy, University Hospitals Leuven, Leuven, Belgium \\ ${ }^{\mathrm{d}}$ Department of Urology, University Hospitals Leuven, Leuven, Belgium
}

\begin{abstract}
.
Background: Local ablative treatments of extracranial metastases are increasingly used in renal cell carcinoma (RCC), but their impact on outcome and toxicity remains unclear.

Objectives: To perform a systematic review on the efficacy and toxicity of stereotactic body radiotherapy (SBRT) and radiofrequency ablation (RFA) for the treatment of distant extracranial RCC-metastases.

Methods: Search strategy: Pubmed, Embase and the national trial register were searched for the combination of metastatic RCC and SBRT or RFA. Eligible studies were original comparative studies with at least 10 patients per treatment arm, published since 2000 and reporting on at least one of: local control, overall or cancer specific survival, symptom control, toxicity. When possible, hazard ratios were calculated from survival curves.

Results and limitations: No eligible studies on RFA were found. Eight studies on SBRT were included, all were nonrandomized and seven were observational. Six included only bone metastases. Radiation regime, treatment site and measured outcomes were heterogeneous and intrinsic risks of bias were high. SBRT, especially single dose 24Gy in the spine, seemed more effective than lower dose SBRT or conventional radiotherapy in achieving local control and pain control. Local control rates were $80-90 \%$. The risk of vertebral compression fracture after SBRT for spinal metastases might be as high as 10-25\% or more, especially at higher doses. Other toxicities were mild.

Conclusion: Due to the poor quality of the existing evidence, no definite recommendations on the use of SBRT in metastatic RCC can be made. SBRT, especially a single high dose, seems well tolerated and efficacious in achieving local control and pain relief, but the risk of vertebral compression fractures in spinal metastases is high. Randomized trials are needed to assess impact on local control, symptom control, survival and toxicity, to determine optimal dosing and assess potential synergistic efficacy or toxicity upon combination with systemic treatment.
\end{abstract}

Keywords: Renal cell carcinoma, metastatic, stereotactic body radiotherapy, systematic review

MeSH headings: Carcinoma, renal cell, neoplasm metastasis, radiosurgery

\footnotetext{
${ }^{*}$ Correspondence to: Benoit Beuselinck, Department of General Medical Oncology, University Hospitals Leuven, Herestraat
} 


\section{INTRODUCTION}

In the treatment of renal cell carcinoma (RCC), as in other cancers, there is a trend towards a more aggressive and often ablative local treatment of metastases [1]. The rationale behind this strategy is twofold. On the one hand there is the increasingly popular hypothesis of an oligometastatic state, where ablative treatment of all metastases could result in definitive cure $[2,3]$. On the other hand, the increasing life expectancy due to better systemic treatments results in the need of durable local symptom control, or potentially the treatment of oligoprogressive metastases in otherwise controlled systemic disease. Although local treatment of metastases with the aim of symptom palliation is well established, the place of local ablative treatments remains unclear. In RCC, complete metastasectomy is recommended as treatment of choice in patients presenting with limited and resectable disease after a long disease free interval [4-6]. Although metastasectomy is by now well established in the treatment of RCC, this guideline is based on observational retrospective studies with high selection bias. Other local ablative treatments, for which less evidence is available, are now being increasingly used: stereotactic body radiotherapy (SBRT), radiofrequency ablation (RFA), thermal ablation, cryoablation, laser resection... of these, SBRT and to a lesser extent RFA are the most reported.

RCCs have historically been considered to be radioresistant tumors, because of the poor response of RCC-cellines to radiation in vitro and the disappointing results of conventional radiotherapy (CRT) in the (neo)adjuvant setting [7-12]. However, the mechanism of cell death at high-dose per fraction as in SBRT, is different from that of cell death caused by CRT and seems independent of intrinsic radiosensitivity $[13,14]$. Conventionally fractionated radiotherapy at $1.8-3 \mathrm{~Gy} /$ fraction ( $\mathrm{fx}$ ) causes tumor cell death through oxygen-dependent DNA-damage. Meanwhile the transient waves of hypoxia result in upregulation of angiogenic factors, thus protecting tumor endothelium. Single doses of 15-20Gy/fx however, cause a rapid destruction of the microvasculature, which could cause sublethal radiation-induced damage in cancer cells to become lethal. Another rare but welcome side effect of SBRT is the abscopal effect [15]. This effect is best described as radiation causing tumor regression at non-irradiated sites, which occurs likely through enhancement of tumor-specific immunity. The incidence is unknown, but it seems more frequent in immunogenic tumors such as RCC and melanoma $[16,17]$.

In primary RCC, RFA can be used as an alternative to (partial) nephrectomy in patients presenting with small cortical tumors that are poor candidates for surgery, although non-inferiority to surgery has not yet been conclusively demonstrated [5, 18]. The technique is currently being used for treatment of metastases as well, both in- and outside the kidney [19].

In short, of all local ablative metastasis treatments in RCC, metastasectomy is the only with a well-established role. SBRT and to a lesser extent RFA are gaining popularity. Dabestani et al. have recently published an excellent review on RCCmetastasectomy $[6,20]$. Intracranial metastases in RCC are usually treated according to tumor-agnostic guidelines [21]. Stereotactic radiotherapy for intraand extracranial metastases in RCC has been systematically reviewed by Kothari et al in 2015 [22]. However only one comparative study was included for extracranial metastases [23].

We wished to systematically review the efficacy and toxicity of the treatment of distant extracranial metastases in RCC, with SBRT or RFA, considering only comparative studies.

\section{METHODS}

The review was done according to the preferred reporting items of systematic reviews and metaanalyses (PRISMA) guidelines [24].

We searched Pubmed and Embase for articles published from 2000 till August 2017, without language restrictions. As search terms, we used the combination of "renal cell carcinoma", "metastatic" and "stereotactic radiotherapy or radiofrequency ablation". For all three terms, both MeSH/emtree terms and free text words were used. Alternative search terms for RCC included the different histological variants as described in the 2016 ESMO guideline [5]. The exact search strategy is provided in the supplementary materials. Reference lists of selected studies were screened for extra publications. www.clinicaltrials.gov was searched for the combination of "renal cell carcinoma, metastatic" and "radiotherapy".

Eligibility criteria for studies to be included were: RCC with distant extracranial metastases, treated with SBRT or RFA and compared with other local therapy, systemic therapy or no therapy. At least 
one of the following outcomes had to be reported: local control rate (LCR), overall or cancer specific survival, symptom control or toxicity. The scheme of SBRT and control therapy had to be reported. Only original studies with at least ten patients per treatment arm were accepted. Studies with mixed tumor types, intracranial metastases or local relapse could be included if separate results were reported for extracranial RCC-metastases. If studies reported on overlapping patient cohorts, the most recent one was selected.

The first author was responsible for the search, study selection and data extraction. In cases of doubt, a second author (BB) reviewed abstract and full text and decisions were made by consensus. Data were extracted using a pre-designed form, provided in the supplementary materials. We extracted data on study design, time period, center, funding, participants, intervention and comparator, outcome (LCR, overall or cancer specific survival, symptom control, toxicity) and systematic differences between treatment groups that could influence outcome. If hazard ratios were not reported, they were calculated wherever possible using the spreadsheet developed by Matthew Sydes [25]. This was done using presented Kaplan Meier curves, presuming a constant hazard ratio and censoring rate.

The risk of bias in randomized controlled trials was assessed with the Cochrane Collaboration risk of bias instrument and that of non-randomized comparative studies with the Cochrane Non-Randomized studies group [26]. We predefined and screened for other possible sources of bias between treatment groups that are relevant for this setting: histology, performance status, Fuhrman grade, tumor volume, treatment site, previous, concomitant or later therapy and variable fractionation regimens within the same treatment arm.

\section{RESULTS}

The selection process of eligible studies is shown in Fig. 1. We identified no studies on RFA that met the eligibility criteria. Eight studies on SBRT were included in the final review [23, 27-33]. Results are summarized in Table 1. One study was an abstract only, one was a poster [27, 29]. Six considered only bone metastases, mostly spine, two included mixed locations [27, 32]. One study was prospective [28]. All studies included RCC only. Reporting on systematic differences between treatment groups was limited: four studies reported performance status, four age, four gender, four histology, five previous therapy, two concomitant therapy, two subsequent therapy, five target volume and three biological equivalent dose. No study reported metastatic load outside the treated region, Fuhrman grade or TNM-stage.

Metastatic location, SBRT regimen, comparator intervention and measured outcomes were heterogeneous between studies. In several cases, different SBRT or CRT regimens were used within the same treatment arm. It was therefore not possible to perform a meta-analysis or even to construct a forest plot summarizing the results. Only three studies

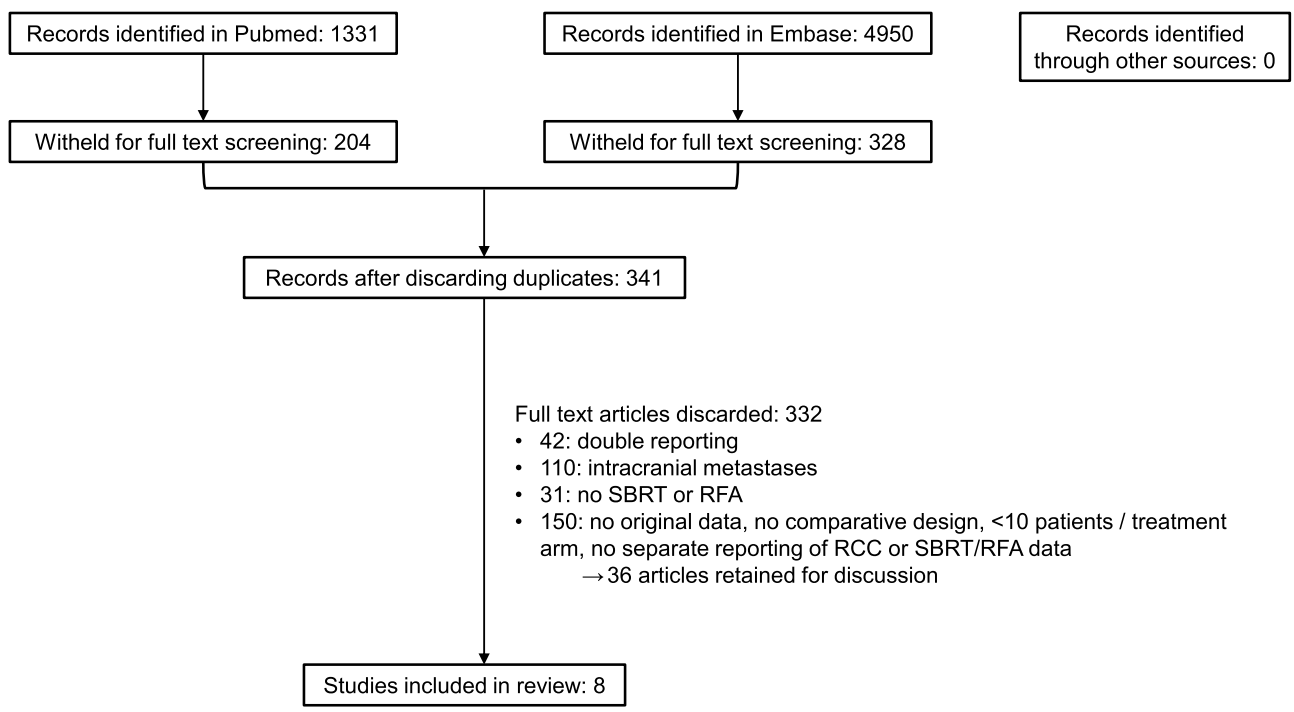

Fig. 1. Flow chart of study selection after literature search. 


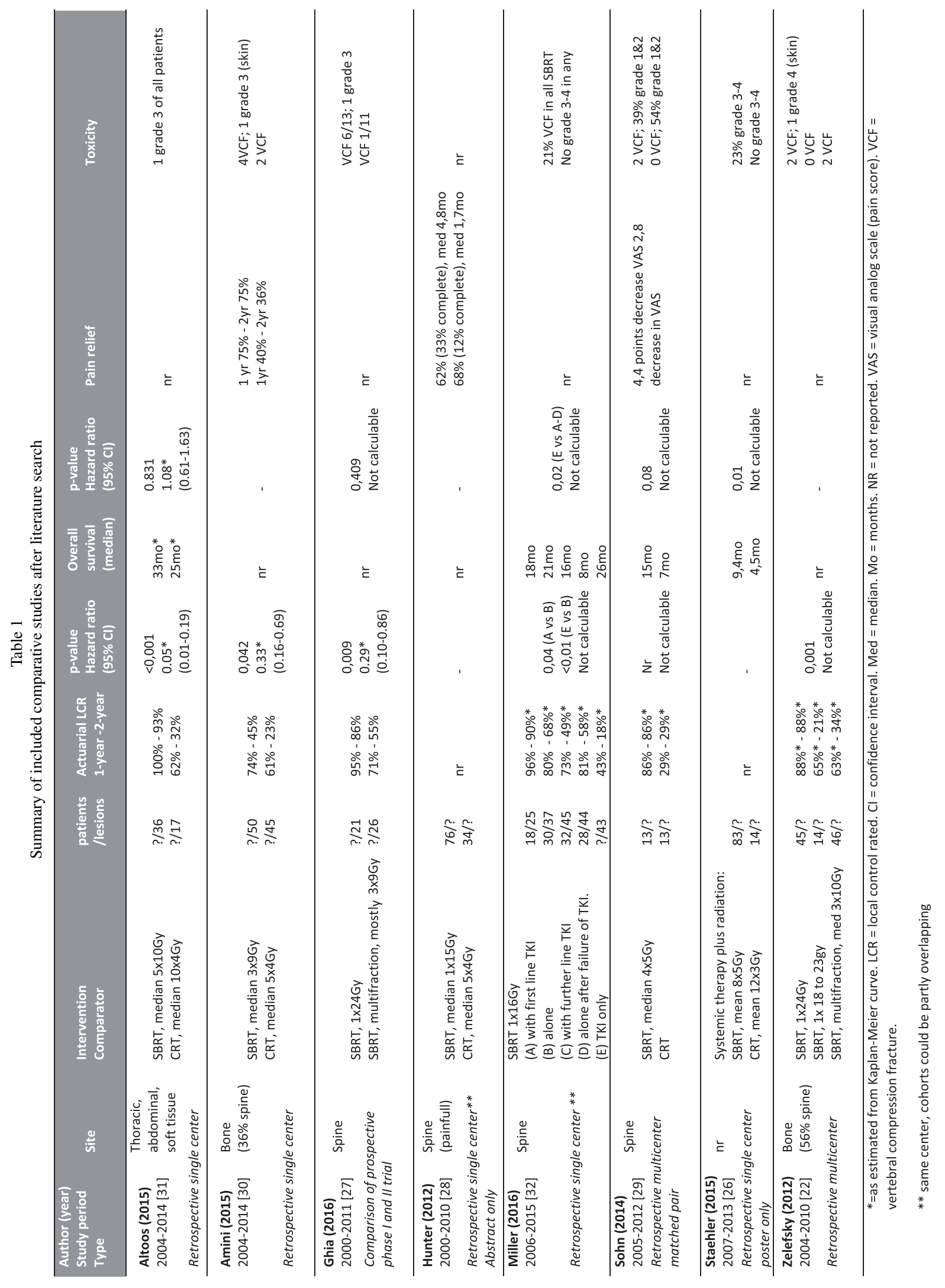


presented sufficient data to calculate hazard ratios. As knowing the hazard ratios would still not allow us to perform a meta-analysis, the study authors were not contacted. Instead, we provide a narrative synthesis of the results.

\section{Local control}

\section{Spinal metastases}

Two studies reported superior local control of spine metastases with single dose $24 \mathrm{~Gy}$ versus SBRT with multiple fractions or lower dose single fraction. Zelefsky et al. reported an $88 \%$ 1-year LCR after single dose $24 \mathrm{~Gy}$, versus $65 \%$ and $63 \%$ with single dose 18-23Gy or 3x10Gy/fx [23]. Interestingly, the Kaplan Meier curves for time to relapse were overlapping for the low single dose and hypofractionated cohorts, whereas the relapse curve for the high single dose was clearly superior. Ghia et al. found a 1 -year LCR of $95 \%$ after single dose $24 \mathrm{~Gy}$, versus $71 \%$ after a hypofractionated SBRT regimen (mostly $3 \times 9 G y)$ [28]. In this study, single dose SBRT was the only significant predictor for superior local control on multivariate analysis.

Two studies reported superior local control of painful spinal metastases for treatment with hypofractionated SBRT versus conventionally fractionated radiotherapy regimens. SBRT doses were lower in these studies. The first found a 1-year LCR of $86 \%$ versus $29 \%$ in patients treated with median $4 \times 5$ Gy SBRT versus a conventionally fractionated regime [30]. The second reported $74 \%$ versus $61 \% 1$ year LCR after median 3x9Gy SBRT versus median 5x4Gy CRT [31].

One study, by Miller et al., compared single fraction $16 \mathrm{~Gy}$ with or without a tyrosine kinase inhibitor (TKI). In first line, the combination was better than SBRT alone (1-year LCR 96\% versus 80\%) [33]. In any line, SBRT with or without TKI was better than TKI alone.

\section{Non-osseous metastases}

One study included thoracic, abdominal and soft tissue metastases. It reported $100 \%$ versus $62 \% 1$ year LCR for median 5x10Gy/fx SBRT $(n=36)$ versus median 10x4Gy/fx CRT $(n=17)$ [32]. As it reported, almost half of the CRT patients received only a low irradiation dose with palliative intent.

\section{Overall survival}

Five studies reported overall survival data. However, none of these had curative treatment of all metastases as main goal and none reported on metastatic load outside the treated location. Three studies did not find a significant difference in overall survival [28, 30, 32]. Two reported higher overall survival for SBRT compared with no or conventional radiotherapy respectively [27, 33]. In both, patients also received variable systemic therapies.

\section{Symptom control}

Three studies reported on the efficacy of SBRT versus CBRT on symptomatic bone metastases (mostly spine). The first showed more patients experiencing pain control with median 3x9Gy/fx SBRT versus median 5x4Gy/fx CRT: $75 \%$ versus $36 \%$ after two years [31]. The second reported al longer duration of pain relief in patients treated with single dose 15Gy versus median 5x4Gy/fx CBRT (4.8 versus 1.7 months, $p=0.095$ ) [29]. There was a trend towards more complete pain relief (33\% versus 12\%). The third study reported a significantly larger drop in pain scores of patients treated with SBRT at median $4 \times 5 \mathrm{~Gy} / \mathrm{fx}$ versus conventionally fractionated CBRT, without a significant difference in the number of patients experiencing pain relief and a similar number of patients requiring new local intervention later on ( 2 and 3 of 13) [30].

\section{Adverse events}

\section{Six studies reported on adverse events}

The most notable adverse event was the occurrence of vertebral compression fractures (VCF) in patients with spinal metastases. Due to different dosing regimens, the risk is difficult to estimate. One study reported however an incidence of $21 \%$ in 108 patients treated with single dose 16Gy [33], another an incidence of $46 \%$ in 13 patients treated with single dose 24Gy [28] and a third 5\% in patients treated with single dose 18-24Gy [23]. In different hypofractionated SBRT regimens, the weighed incidence was $13 \%[23,28,30]$. In two studies explicitly reporting on compression fractures in patients treated with CRT, the weighed incidence was $6.5 \%$. No data on the use of bone protective agents (zolendronic acid, denosumab) were available.

Other toxicities were generally mild. In patients treated with single dose $24 \mathrm{~Gy}$, respectively $1 / 13$ and 1/45 grade 3-4 toxicities were reported. Three studies comparing SBRT with CRT reported no difference in toxicities and no grade 4 toxicities [30-32].

Two studies reported on concomitant systemic therapy and SBRT. In one, irradiating spine 
Table 2

Potential biases in the included studies

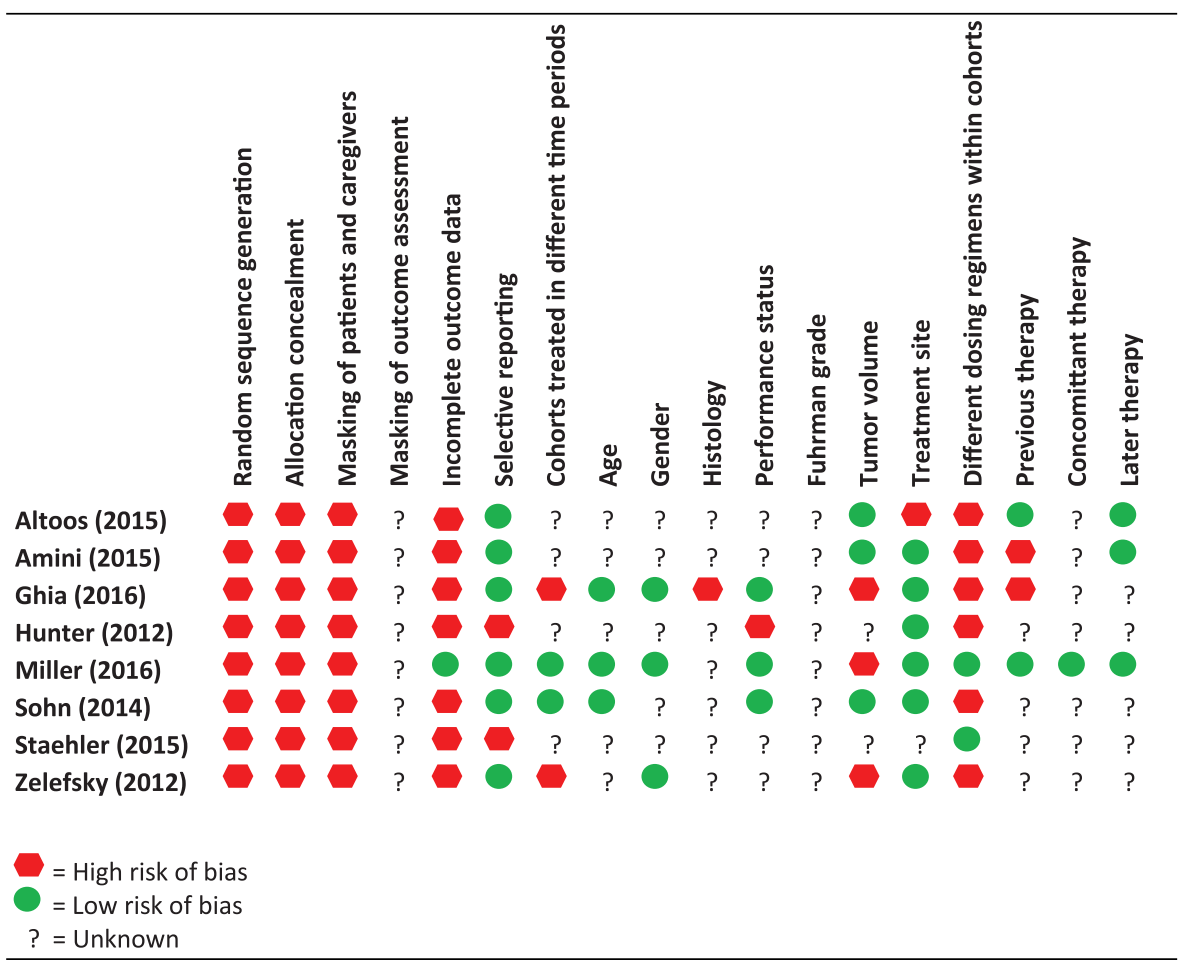

metastases, only grade 1-2 toxicities occurred, both in the groups treated with SBRT alone and SBRT with TKI (tyrosine kinase inhibitor) [33]. In the other study however, that did not provide location, $23 \%$ grade 3 toxicities occurred in the group treated with SBRT and systemic therapy, compared to none in the CRT with systemic therapy group [27]. It was not clear which systemic treatments were used in both groups.

\section{Risk of bias}

Potential sources of bias for each study are shown in Table 2. As all but one study were retrospective observational studies, the intrinsic risk of bias is very high. Moreover, as mentioned above, reporting of important clinical variables was often incomplete and radiation regimens often differed within the same treatment arm of a study. As SBRT is a relatively new technique, we can also assume a time bias with SBRT-patients treated more recently, when both radiation techniques and systemic therapy had improved. For an example, Ghia found better local control after single dose 24Gy than after hypofractionated SBRT, but also reported that the more recently treated single dose cohort achieved better coverage of the planned target volume [28].

\section{DISCUSSION}

We aimed to assess the impact on outcome and toxicity of SBRT for extracranial RCC-metastases. However, we identified only eight eligible comparative studies, that were all but one retrospective and observational in nature. Sample sizes were small and used treatment regimens differed substantially between and within studies. All results should therefore be interpreted with utmost caution. Moreover, all but two studies reported only on bone metastases so results may not be generalizable to other locations. The results are discussed in the context of other published literature.

\section{Overall survival}

Although locally ablative techniques are hypothesized to prolong survival, none of the studies aimed explicitly to treat all metastases or oligoprogressive disease. Therefore, even when neglecting other biases, the effect on overall survival cannot be estimated. In one non-comparative RCC-study, 12 patients had all metastases treated with SBRT. After two years their LCR was $100 \%$, but $64 \%$ had progressed at other sites [34]. Another large study 
reported significantly better local control in patients treated with curative versus palliative intent, but the numerical difference was not large (95\% versus $88 \%$ ) and overall survival data were not provided [35]. There are no comparative studies on SBRT versus metastasectomy, the latter being considered standard therapy though without a proven survival advantage [6]. One randomized trial exists, comparing local consolidative therapy with maintenance therapy in oligometastatic non-small cell lung carcinoma after first-line systemic therapy [36]. The investigators found a significantly longer progression free survival in patients that received local treatment, which could be SBRT, intermediate hypofractionated RT, radiochemotherapy or metastasectomy.

\section{Local control}

The most robust outcome data were on local control. All six studies reporting on local control were in favor of SBRT versus CRT or TKI and of high dose SBRT versus low dose SBRT. Most included only bone metastases. One year LCRs varied between $63 \%$ and $100 \%$. Importantly, there seems to be a steep dose-response curve after SBRT. Zelefky reported the best LCR for treatment with single dose 24Gy and inferior, overlapping relapse curves for treatment with single dose 18 to $23 \mathrm{~Gy}$ or $3 \times 10 \mathrm{~Gy} / \mathrm{fx}$ [23]. Ghia also reported better outcome after single dose $24 \mathrm{~Gy}$ versus $3 \times 9 \mathrm{~Gy} / \mathrm{fx}$ [28]. These findings are consistent with other non-comparative studies. Greco et al noted a steep dose response curve for RCC-metastases at different locations, treated with single-dose 18-24Gy: LCR was $80 \%$ after $23-24$ Gy and $37 \%$ with less [37]. Recent reviews including mixed histologies, have suggested SBRT could result in 90\% local control in spinal metastases treated with high dose single fraction, and in about $80 \%$ local control in liver and lung metastases treated with hypofractionated regimens $[3,38,39]$. Non-comparative retrospective series on SBRT for RCC-bone metastases report local control rates of $70-90 \%$ at one or two years, using different fractionation regimens [40-45]. Other series including non-bone metastases find similar LCRs $[34,35,46-50]$. In a recent systematic review of mainly non-comparative series, the weighted LCR for extracranial RCC-metastases was 89\% [22]. Two series that included both bone and non-bone lesions, explicitly reported a superior LCR in non-bone metastases. One found a median progression free survival of 15 versus 42 months in 89 bone and 48 non-bone lesions [46]. The other found a 1-year LCR of $86 \%$ versus $93 \%$ for spine versus non-spine (total 175 lesions) [35]. Patients with spinal metastases and instability or neurological dysfunction were typically excluded, no conclusions can be drawn for this population. In one non-comparative study observational study, 55 patients with painful, instable or threatening spinal metastases were treated with single fraction 19-20Gy and TKI. One and two-year local control rate were $94 \%$ and $90 \%$ [51].

\section{Symptom control}

There was evidence of superior symptom control in bone metastases for relatively low dose SBRT compared to hyper- or hypofractionated CRT. Three studies showed respectively more patients experiencing pain relief, more patients experiencing complete pain relief and a higher drop in pain score. Other series on spinal RCC-metastases have reported $46 \%$ to $100 \%$ improvement in pain; one found $52 \%$ to be completely pain free after one year versus $23 \%$ before start of treatment [40, 42-45, 51]. A review on SBRT for spine metastases of mixed histology found an average complete response rate of 54\% [39]. A randomized phase III trial, RTOG 0631, is currently evaluating the effect of single dose 16Gy SBRT versus single dose 8Gy CRT in painful spinal metastases of mixed histology.

\section{Adverse events}

SBRT was well tolerated according to all studies. This is in line with other, non-comparative studies all reporting limited toxicity $[34,35,40-44,46,47$, $52,53]$. However, for spinal metastases the risk of VCF was substantial (incidence $0-46 \%$ ), with the largest study in 151 lesions reporting $21 \% \mathrm{VCF}$ after single dose 16Gy [33]. Thibault et al. assessed the risk of VCF in 227 RCC-lesions treated with median 1x19Gy/fx. They found and incidence of 16\%: the risk of a de novo VCF was 7\%, that of progression of a preexisting VCF 51\%. Importantly, there was a strong relationship with dose per fraction, that remained highly significant after multivariate analysis: the risk was $43 \%$ after $24 \mathrm{~Gy} / \mathrm{fx}, 24 \%$ after $20-23 \mathrm{~Gy} / \mathrm{fx}$ and $12 \%$ after $\leq 19 \mathrm{~Gy} / \mathrm{fx}$ [52]. In another large series that included tumors of mixed histology, the incidence was $11 \%$, with $2 / 3$ being de novo VCF. The risk was linked to dose per fraction $\geq 20 \mathrm{~Gy}$ and osteolytic lesions, as are typically found in RCC [54, 55]. A systematic review of mixed histologies found a weighted incidence of $9.4 \%$ [39]. Another feared complication 
of spinal radiotherapy is myelopathy, which is often the dose-limiting factor for the less accurate CRT. In the included series, only one case of grade 3 radiculopathy was mentioned [28]. For mixed histologies and different dosing regimens, the risk may be as low as $0.2 \%$ [39].

\section{Combination therapy}

A recent area of active research is the combination of SBRT with systemic therapies. One hypothesis is that in oligoprogressive disease, local treatment of resistant lesions could allow continuation of a systemic treatment that is still effective for other metastatic sites. Another rationale is that of expected synergy between SBRT and systemic therapies. As SBRT has shown to stimulate tumor-specific immunity, testified by the rare abscopal effect, it might enhance the effect of other immunomodulatory drugs [56, 57]. A phase I and II trial combining high dose interleukin 2 (IL2) with SBRT showed increased response rates to IL2 compared with historical data $[58,59]$. Numerous other trials are currently ongoing [60-65]. The safety of combining SBRT with systemic therapies remains unclear [66]. In the IL2studies "only expected toxicities" were reported. Miller reported similar, limited toxicity in 101 RCCpatients treated with single fraction SBRT with or without TKI [33]. In a phase I dose escalation trial, no dose limiting toxicities occurred in 13 RCC-patients treated with hypofractionated SBRT and pazopanib [67]. Several case reports have however been published concerning toxicities of combination strategies [68-70]. The risk is probably site dependent, as illustrated by a case of cardiac failure on sunitinib after previous irradiation of the chest wall and a case of bowel perforation on sorafenib after irradiation of L3-L5 [70, 71].

\section{CONCLUSION}

We aimed to systematically review the efficacy and toxicity of SBRT and RFA for treatment of extracranial RCC-metastases. No studies on RFA that met the inclusion criterion were found. As for SBRT, due to the sparsity, heterogeneity and low quality of available data, it is not possible to make definite recommendations on its use. SBRT seems superior over CRT for local control and may result in better pain control. As it is generally well tolerated and more patient-friendly than conventionally fractionated schemes, SBRT is a good alternative to
CRT in these settings. Optimal dosing needs to be determined, but in spine a single fraction of 24Gy seems superior over other SBRT schemes. As every fraction of SBRT requires the same accuracy and surpasses the safety threshold for critical normal organs according to the AAPM guidelines, there seems to be no clear advantage of multiple fraction schemes. However, in spinal metastases the risk of VCF is significant, especially at the more effective dose of 1x24Gy. Its incidence, clinical impact and optimal dosing to reduce the risk need further investigation.

There are no comparative data on SBRT versus surgery in the settings of curative intent or spinal metastases that are unstable or cause neurological deficit. In the latter case, surgery has priority if feasible.

\section{CONFLICT OF INTEREST STATEMENT}

Benoit Beuselinck received honoraria from Amgen, Pfizer, Janssen and Bayer and is an investigator of the EudraCT: 2011-006085-40/MetaSun trial supported by Pfizer. The other authors have no conflict of interest to report.

\section{ACKNOWLEDGMENTS}

Annelies Verbiest has received a grant from Kom op tegen Kanker (Stand up to Cancer), the Flemish cancer society.

\section{SUPPLEMENTARY MATERIAL}

The supplementary material is available in the electronic version of this article: http://dx.doi.org/ 10.3233/KCA-170023.

\section{REFERENCES}

[1] Meyer C, Trinh Q-D, Vetterlein M, Löppenberg B, Adollah F, Seisen T, et al. Trends of Metastasectomy for Metastatic Renal Cell Carcinoma and Their Impact on Overall Survival. The Journal of Urology 2016;195(4).

[2] Palma DA, Salama JK, Lo SS, Senan S, Treasure T, Govindan R, et al. The oligometastatic state - separating truth from wishful thinking. Nat Rev Clin Oncol 2014;11(9):549-57.

[3] Tree AC, Khoo VS, Eeles RA, Ahmed M, Dearnaley DP, Hawkins MA, et al. Stereotactic body radiotherapy for oligometastases. The Lancet Oncology 2013;14(1):e28e37.

[4] Ljungberg B, Bensalah K, Canfield S, Dabestani S, Hofmann F, Hora M, et al. EAU guidelines on renal cell carcinoma: 2014 update. Eur Urol 2015;67(5):913-24.

[5] Escudier B, Porta C, Schmidinger M, Rioux-Leclercq N, Bex A, Khoo V, et al. Renal cell carcinoma: ESMO Clinical 
Practice Guidelines for diagnosis, treatment and follow-up. Ann Oncol 2016;27(suppl 5):v58-v68.

[6] Dabestani S, Marconi L, Bex A. Metastasis therapies for renal cancer. Curr Opin Urol 2016;26(6):566-72.

[7] Deschavanne PJ, Fertil B. A review of human cell radiosensitivity in vitro. Int $\mathrm{J}$ Radiat Oncol Biol Phys 1996;34(1):251-66.

[8] Van Der Werf-Messing B. Proceedings: Carcinoma of the kidney. Cancer 1973;32(5):1056-61.

[9] Juusela H, Malmio K, Alfthan O, Oravisto KJ. Preoperative Irradiation in the Treatment of Renal Adenocarcinoma. Scandinavian Journal of Urology and Nephrology 2010;11(3):277-81.

[10] Tunio MA, Hashmi A, Rafi M. Need for a new trial to evaluate postoperative radiotherapy in renal cell carcinoma: A meta-analysis of randomized controlled trials. Ann Oncol 2010;21(9):1839-45.

[11] Kjaer M, Frederiksen PL, Engelholm SA. Postoperative radiotherapy in stage II and III renal adenocarcinoma. A randomized trial by the Copenhagen Renal Cancer Study Group. International Journal of Radiation Oncology, Biology, Physics 1987;13(5):665-72.

[12] Finney R. An evaluation of postoperative radiotherapy in hypernephroma treatment-a clinical trial. Cancer 1973;32(6):1332-40.

[13] De Meerleer G, Khoo V, Escudier B, Joniau S, Bossi A, Ost $\mathrm{P}$, et al. Radiotherapy for renal-cell carcinoma. The Lancet Oncology 2014;15(4):e170-e7.

[14] Siva S, Kothari G, Muacevic A, Louie AV, Slotman BJ, Teh BS, et al. Radiotherapy for renal cell carcinoma: Renaissance of an overlooked approach. Nat Rev Urol 2017;14(9):549-63.

[15] Reynders K, Illidge I, Siva S, Chang J, De Ruysscher D. The abscopal effect of local radiotherapy in the clinic: A systematic review on its occurrence. Radiotherapy and Oncology 2015;115:S583-S4.

[16] Wersall PJ, Blomgren H, Pisa P, Lax I, Kalkner KM, Svedman C. Regression of non-irradiated metastases after extracranial stereotactic radiotherapy in metastatic renal cell carcinoma. Acta Oncologica 2006;45(4): 493-7.

[17] Ribeiro Gomes J, Schmerling RA, Haddad CK, Racy DJ, Ferrigno R, Gil E, et al. Analysis of the Abscopal Effect With Anti-PD1 Therapy in Patients With Metastatic Solid Tumors. Journal of immunotherapy (Hagerstown, Md: 1997) 2016;39(9):367-72.

[18] Ljungberg B, Albiges L, Bensalah K, Bex A, Giles $\mathrm{RH}$, Hora $\mathrm{M}$, et al. Members of the RCC guidelines panel. EAU guidelines on renal cell carcinoma. Retrieved from: http://uroweborg/guideline/renalcell-carcinoma/2017-11-01.

[19] Hiraki T, Kanazawa S. Lung radiofrequency ablation: Potential as a therapy to oligometastasis and oligorecurrence. Pulmonary Medicine 2012;2012:196173.

[20] Dabestani S, Marconi L, Hofmann F, Stewart F, Lam TBL, Canfield SE, et al. Local treatments for metastases of renal cell carcinoma: A systematic review. The Lancet Oncology 2014;15(12):e549-e61.

[21] Soffietti R, Abacioglu U, Baumert B, Combs SE, Kinhult S, Kros JM, et al. Diagnosis and treatment of brain metastases from solid tumors: Guidelines from the European Association of Neuro-Oncology (EANO). Neuro Oncol 2017;19(2):162-74.

[22] Kothari G, Foroudi F, Gill S, Corcoran NM, Siva S. Outcomes of stereotactic radiotherapy for cranial and extracranial metastatic renal cell carcinoma: A systematic review. Acta Oncol 2015;54(2):148-57.

[23] Zelefsky MJ, Greco C, Motzer R, Magsanoc JM, Pei $\mathrm{X}$, Lovelock $\mathrm{M}$, et al. Tumor control outcomes after hypofractionated and single-dose stereotactic image-guided intensity-modulated radiotherapy for extracranial metastases from renal cell carcinoma. Int J Radiat Oncol Biol Phys 2012;82(5):1744-8

[24] Liberati A, Altman DG, Tetzlaff J, Mulrow C, Gotzsche PC, Ioannidis JP, et al. The PRISMA statement for reporting systematic reviews and meta-analyses of studies that evaluate health care interventions: Explanation and elaboration. PLoS Med 2009;6(7):e1000100.

[25] Tierney JF, Stewart LA, Ghersi D, Burdett S, Sydes MR. Practical methods for incorporating summary time-to-event data into meta-analysis. Trials 2007;8:16.

[26] Sterne JA, Hernan MA, Reeves BC, Savovic J, Berkman ND, Viswanathan M, et al. ROBINS-I: A tool for assessing risk of bias in non-randomised studies of interventions. BMJ 2016;355:i4919.

[27] Staehler MD, Lisa B, Nuhn P, Schlenker B, Wilkowski R. Comparison of simultaneous high dose stereotactic radiotherapy with normofractionated radiotherapy in patients with metastatic renal cell carcinoma under systemic therapy. Journal of Clinical Oncology 2015;33(7).

[28] Ghia AJ, Chang EL, Bishop AJ, Pan HY, Boehling NS, Amini B, et al. Single-fraction versus multifraction spinal stereotactic radiosurgery for spinal metastases from renal cell carcinoma: Secondary analysis of Phase I/II trials. J Neurosurg Spine 2016;24(5):829-36.

[29] Hunter GK, Balagamwala EH, Koyfman SA, Bledsoe T, Sheplan LJ, Reddy CA, et al. The efficacy of external beam radiotherapy and stereotactic body radiotherapy for painful spinal metastases from renal cell carcinoma. Pract Radiat Oncol 2012;2(4):e95-e100.

[30] Sohn S, Chung CK, Sohn MJ, Chang UK, Kim SH, Kim J, et al. Stereotactic radiosurgery compared with external radiation therapy as a primary treatment in spine metastasis from renal cell carcinoma: A multicenter, matched-pair study. J Neurooncol 2014;119(1):121-8.

[31] Amini A, Altoos B, Bourlon MT, Bedrick E, Bhatia S, Kessler ER, et al. Local control rates of metastatic renal cell carcinoma (RCC) to the bone using stereotactic body radiation therapy: Is RCC truly radioresistant? Pract Radiat Oncol 2015;5(6):e589-e96.

[32] Altoos B, Amini A, Yacoub M, Bourlon MT, Kessler EE, Flaig TW, et al. Local Control Rates of Metastatic Renal Cell Carcinoma (RCC) to Thoracic, Abdominal, and Soft Tissue Lesions Using Stereotactic Body Radiotherapy (SBRT). Radiat Oncol 2015;10:218.

[33] Miller JA, Balagamwala EH, Angelov L, Suh JH, Rini B, Garcia JA, et al. Spine stereotactic radiosurgery with concurrent tyrosine kinase inhibitors for metastatic renal cell carcinoma. J Neurosurg Spine 2016;25(6):766-74.

[34] Ranck MC, Golden DW, Corbin KS, Hasselle MD, Liauw SL, Stadler WM, et al. Stereotactic body radiotherapy for the treatment of oligometastatic renal cell carcinoma. American Journal of Clinical Oncology 2013;36(6):589-95.

[35] Wang CJ, Christie A, Lin MH, Jung M, Weix D, Huelsmann L, et al. Safety and Efficacy of Stereotactic Ablative Radiation Therapy for Renal Cell Carcinoma Extracranial Metastases. Int J Radiat Oncol Biol Phys 2017;98(1):91100.

[36] Gomez D, Blumenschein G, Lee J, Hernandez M, Ross Camidge D, Doebele R, et al. Local consolidative ther- 
apy versus maintenance therapy or observation for patients with oligometastatic non-small-cell lung cancer without progression after first-line systemic therapy: A multicentre, randomised, controlled, phase 2 study. Lancet Oncol 2016;17(12):1672-82.

[37] Greco C, Zelefsky MJ, Lovelock M, Fuks Z, Hunt M, Rosenzweig K, et al. Predictors of local control after single-dose stereotactic image-guided intensity-modulated radiotherapy for extracranial metastases. Int J Radiat Oncol Biol Phys 2011;79(4):1151-7.

[38] Greco C, Pares O, Pimentel N, Moser E, Louro V, Morales $\mathrm{X}$, et al. Spinal metastases: From conventional fractionated radiotherapy to single-dose SBRT. Rep Pract Oncol Radiother 2015;20(6):454-63.

[39] Husain ZA, Sahgal A, De Salles A, Funaro M, Glover J, Hayashi M, et al. Stereotactic body radiotherapy for de novo spinal metastases: Systematic review. J Neurosurg Spine 2017;27(3):295-302.

[40] Gerszten PC, Burton SA, Ozhasoglu C, Vogel W. Stereotactic radiosurgery for spinal metastases from renal cell carcinoma. J Neurosurg Spine 2005;3:288-95.

[41] Balagamwala EH, Angelov L, Koyfman SA, Suh JH, Reddy CA, Djemil T, et al. Single-fraction stereotactic body radiotherapy for spinal metastases from renal cell carcinoma. J Neurosurg Spine 2012;17(6):556-64.

[42] Jhaveri PM, Teh BS, Paulino AC, Blanco AI, Lo SS, Butler $\mathrm{EB}$, et al. A dose-response relationship for time to bone pain resolution after stereotactic body radiotherapy (SBRT) for renal cell carcinoma (RCC) bony metastases. Acta Oncol 2012;51(5):584-8.

[43] Nguyen QN, Shiu AS, Rhines LD, Wang H, Allen PK, Wang XS, et al. Management of spinal metastases from renal cell carcinoma using stereotactic body radiotherapy. Int J Radiat Oncol Biol Phys 2010;76(4):1185-92.

[44] Sellin JN, Reichardt W, Bishop AJ, Suki D, Rhines LD, Settle SH, et al. Factors affecting survival in 37 consecutive patients undergoing de novo stereotactic radiosurgery for contiguous sites of vertebral body metastasis from renal cell carcinoma. J Neurosurg Spine 2015;22(1):52-9.

[45] Serrand J, Sunyach M, Negrier S, Carrie C. Stereotactic body radiation therapy (SBRT) on spine metastases from renal cell carcinoma (RCC): Clinical results and impact of upfront vs salvage SBRT. JCO (supp) 2016:e16073.

[46] Meyer E, Stefan D, Pasquier D, Bernadou G, Calais G, Carrie C, et al. Stereotactic radiotherapy (SRT) for oligometastatic $(\mathrm{OM})$ relapse and metastatic oligoprogression (OP) in renal cell carcinoma (RCC) patients (pts): A study of the GETUG group. Journal of Clinical Oncology 2016;34.

[47] Teh B, Bloch C, Galli-Guevara M, Doh L, Richardson S, Chiang $\mathrm{S}$, et al. The treatment of primary and metastatic renal cell carcinoma (RCC) with image-guided stereotactic body radiation therapy (SBRT). Biomed Imaging Interv $\mathbf{J}$ 2007;3(1):e6.

[48] Grossman CE, Okunieff P, Brasacchio RA, Katz AW, Singh DP, Usuki KY, et al. Stereotactic body radiation therapy for oligometastatic renal cell carcinoma or melanoma: Prognostic factors and outcomes. International Journal of Radiation Oncology Biology Physics 2015;93(3):E202.

[49] Rieber J, Andratschke N, Blanck O, Duma M, Ganswindt U, Imhoff D, et al. SBRT for lung metastases: Detailed subgroup analysis of 700 patients diagnosed with 963 lung metastases. Radiotherapy and Oncology 2015;115:S27-S8.

[50] Stinauer MA, Kavanagh B, Schefter T, Gonzalez R, Flaig $\mathrm{T}$, Lewis $\mathrm{K}$, et al. Stereotactic body radiation therapy for melanoma and renal cell carcinoma: Impact of single fraction equivalent dose on local control. International Journal of Radiation Oncology Biology Physics 2010;78(3):S190S1.

[51] Staehler M, Haseke N, Nuhn P, Tullmann C, Karl A, Siebels $\mathrm{M}$, et al. Simultaneous anti-angiogenic therapy and singlefraction radiosurgery in clinically relevant metastases from renal cell carcinoma. BJU Int 2011;108(5):673-8.

[52] Thibault I, Atenafu EG, Chang E, Chao S, Al-Omair A, Boehling N, et al. Factors Influencing Vertebral Compression Fracture Specific to Renal Cell Carcinoma Spinal Metastases After Stereotactic Body Radiation Therapy: A Multi-institutional Study. International Journal of Radiation Oncology Biology Physics 2014;90(1).

[53] Svedman C, Sandstrom P, Pisa P, Blomgren H, Lax I, Kalkner KM, et al. A prospective Phase II trial of using extracranial stereotactic radiotherapy in primary and metastatic renal cell carcinoma. Acta Oncol 2006;45(7):870-5.

[54] Cunha MV, Al-Omair A, Atenafu EG, Masucci GL, Letourneau D, Korol R, et al. Vertebral compression fracture (VCF) after spine stereotactic body radiation therapy (SBRT): Analysis of predictive factors. International Journal of Radiation Oncology, Biology, Physics 2012;84(3):e343-9.

[55] Zekri J, Ahmed N, Coleman RE, Hancock BW. The skeletal metastatic complications of renal cell carcinoma. Int J Oncol 2001;19(2):379-82

[56] De Wolf K, Vermaelen K, De Meerleer G, Lambrecht BN, Ost $\mathrm{P}$. The potential of radiotherapy to enhance the efficacy of renal cell carcinoma therapy. Oncoimmunology 2015;4(10):e1042198

[57] Singh AK, Winslow TB, Kermany MH, Goritz V, Heit L, Miller A, et al. A Pilot Study of Stereotactic Body Radiation Therapy Combined with Cytoreductive Nephrectomy for Metastatic Renal Cell Carcinoma. Clinical cancer research: An official journal of the American Association for Cancer Research 2017;23(17):5055-65.

[58] Seung SK, Curti BD, Crittenden M, Walker E, Coffey T. Phase 1 study of stereotactic body radiotherapy and Internleuking-2: tumor and immunological responses. Science Translational Medicine 2012;4(137):1-7.

[59] Hannan R, Ishibara D, Louder K, Ahn C. Phase II trial of high-dose Interleukin-2 (IL-2) and stereotactic radiation therapy (SABR) for metastatic clear cell renal cell carcinoma (ccRCC): interim analysis. JCO (supp) 2016:abstract 532.

[60] Medicine UNLo. ClinicalTrials.gov. https://clinicaltrialsgo v/ct2/show/NCT02019576. 2017.

[61] Medicine UNLo. ClinicalTrials.gov. https://clinicaltrialsg ov/ct2/show/NCT01896271. 2017.

[62] Medicine UNLo. ClinicalTrials.gov. https://clinicaltrialsgo v/ct2/show/NCT01884961. 2017.

[63] Medicine UNLo. ClinicalTrials.gov. https://clinicaltrialsgo v/ct2/show/NCT03065179. 2017.

[64] Medicine UNLo. ClinicalTrials.gov. https://clinicaltrialsgo v/ct2/show/NCT02781506. 2017.

[65] Medicine UNLo. ClinicalTrials.gov. https://clinicaltrialsgo v/ct2/show/NCT02864615. 2017.

[66] Kroeze SG, Fritz C, Hoyer M, Lo SS, Ricardi U, Sahgal A, et al. Toxicity of concurrent stereotactic radiotherapy and targeted therapy or immunotherapy: A systematic review. Cancer Treat Rev 2017;53:25-37.

[67] De Wolf K, Rottey S, Vermaelen K, Decaestecker K, Sundahl N, De Lobel L, et al. Combined high dose radiation 
and pazopanib in metastatic renal cell carcinoma: A phase I dose escalation trial. Radiat Oncol 2017;12(1):157.

[68] Yuasa T, Kitsukawa S, Sukegawa G, Yamamoto S, Kudo K, Miyazawa K, et al. Early onset recall pneumonitis during targeted therapy with sunitinib. BMC Cancer 2013;13:3.

[69] Lordick F, Geinitz H, Theisen J, Sendler A, Sarbia M. Increased risk of ischemic bowel complications during treatment with bevacizumab after pelvic irradiation: Report of three cases. Int J Radiat Oncol Biol Phys 2006;64(5):1295-8.
[70] Peters NA, Richel DJ, Verhoeff JJ, Stalpers LJ. Bowel perforation after radiotherapy in a patient receiving sorafenib. J Clin Oncol 2008;26(14):2405-6.

[71] Van Keerberghen CA, Van Wambeke S, Wolter P, Schoffski P, Van Cleemput J, Van Limbergen E, et al. A Case of Severe Acute Cardiac Failure on Sunitinib After LeftSided Thoracal Radiation Therapy. Clin Genitourin Cancer 2017;15(1):e155-e8 